\title{
EDITORIAL
}

\section{La defensa por lo autóctono o la asimilación de lo extranjero. ¿Debe prevalecer lo uno sobre lo otro?}

El cambio de milenio, con tan despampanante bienvenida en todos los países del mundo, de años de preparación, no deja de asombrarnos y enfrentarnos a contradicciones sin solución, la defensa por lo autóctono o la asimilación de lo extranjero, ¿debe prevalecer lo uno sobre lo otro? Lo cierto es que la globalización de las relaciones obliga hoy a una participación diferente, en permanente cambio, un cambio ocasionado, desde mi punto de vista, por la tecnología yen especial por la tecnología de las comunicaciones. En Colombia todavía conservamos la tradición de la alfarería, pero la época de los chasquis pasó a la historia y en su cambio, el teléfono, la radio, la televisión, la intranet y el internet. Sin embargo, exportamos espacialmente vasijas, adornos y demás utensilios en barro, de diseños especialmente precolombinos, y de por medio, el teléfono, como mínimo.

¿De qué vale ser rebeldes a lo nuevo, a la tecnología, importada, por lo geneal?. No es mejor aprovechar lo uno y lo otro, de todas formas la asimilación de lo nuevo, nos es inalcanzable; lo que hoy está al día, mañana no, por otra parte, no hay más camino para escoger. La Universidad no es ajena a todo este acelere y novedad, está obligada a ira la vanguardia, es una exigencia de la sociedad. Claro está que dicha vanguardia siempre estará supeditada a los intereses foráneos; como no somos los productores, en la medida en que aquellos necesiten que tengamos su herramienta, nos la proporcionarán, pero no gratuitamente.

Todo ese andamiaje de ciencia y tecnología alrededor del cual gira nuestra cotidianidad, tiene que ver con la Universidad, tanto en lo material y lo visible, como en lo invisible e intangible, y más si de lo pedagógico se trata, y de una entidad líder y con voz y voto en la educación del país. ¿Se imaginan ustedes la responsabilidad tan grande del rector de éste ente, Universidad Pedagógica Nacional, o del que se sentó, por unos minutos para escribir estas líneas? Por lo pronto, un poco de tranquilidad nos la da el Plan de Desarrollo Institucional 1998-2003, un esfuerzo conjunto y ambicioso en el cual se viene trabajando, con bombos y platillos, para el nuevo milenio.

El mencionado Plan de Desarrollo, por supuesto, pinta una universidad como tal, líder, tanto para lo nacional como para lo global. En palabras textuales, en la visión del Plan dice: "La Universidad será reconocida como la institución universitaria del Estado y de la sociedad colombiana que, interpretando los profundos cambios del entorno nacional e internacional, responde con propuestas al desarrollo y transformación de lo educación, aportando al nuevo Proyecto Político Pedagógico para la educación colombiana. Por medio de este nuevo proyecto, se potencian las estrategias, se inculcan los grandes principios, metas y valores consagrados en la Constitución y se forma un ideal de hombre y ciudadano, un nuevo sujeto histórico".

Son muchas, en verdad, las intenciones en las que está trabajando la Universidad Pedagógica, y la comunicación, ocupa en ellos un importante espacio. Su contribución abarco todos las instancias y acciones, desde las que buscan desarrollar nuevos ambientes y formas apropiados de participación, asociación y convivencia de la comunidad universitaria, hasta las que se proponen la proyección de la Institución en el contexto nacional e internacional; con todas sus implicaciones administrativas, tecnológicas, investigativas y científicas, como lo pueden corroborar la implementación de 
los medios masivos de comunicación en la educación superior y la conexión a redes educativas locales, regionales, nacionales e internacionales.

Las revistas y demás medios impresos, cobran, también, vida en medio de estos propósitos ambiciosos de cambio y progreso. Lúdica Pedagógica es un ejemplo, y pretende reafirmarse y continuar creciendo en favor del desarrollo de lo Educación física nacional, porque, además, es fruto de la madre formadora de sus profesionales en el país.

La Facultad de Educación física, en esta administración, ha expuesto un Proyecto Educativo Institucional y consecuentemente con ello, un Plan de Desarrollo para los próximos tres años. En las páginas interiores le invitamos a consultarlos.

Mario Loaiza Padilla 